\title{
Estimation of Group B Streptococcus Colonization in High-Risk Neonates by PCR and Standard Culture
}

\author{
Fariba Shirvani ${ }^{1, *}$; Nader Shahrochi ${ }^{2}$; Mitra Radfar ${ }^{3}$; Davood Lakestani ${ }^{4}$ \\ ${ }_{1}^{1}$ Pediatric Infections Research Center, Mofid Children's Hospital, Shahid Beheshti University of Medical Sciences, Tehran, IR Iran \\ 2 Department of Biotechnology, Pasteur Institute of Iran, Tehran, IR Iran \\ ${ }^{3}$ Neonatal Intensive Care Unit, Imam Hossein Hospital, Shahid Beheshti University of Medical Sciences, Tehran, IR Iran \\ ${ }^{4}$ Pediatric Ward, Imam Hossein Hospital, Shahid Beheshti University of Medical Sciences, Tehran, IR Iran \\ *Corresponding author: Fariba Shirvani, Pediatric Infections Research Center, Mofid Children's Hospital, Shahid Beheshti University of Medical Sciences, Tehran, IR Iran. Tel: +98- \\ 9123277918, Fax: +98-2122226941, E-mail: shirvanifariba@rocketmail.com
}

Received: January 2, 2014; Revised: January 31, 2014; Accepted: March 17, 2014

\begin{abstract}
Background: Group B Streptococcus (GBS) (Streptococcus agalactiae) is the leading cause of morbidity and mortality of newborn infants considered a leading factor causing septicemia after birth. The standard method for the diagnosis of GBS colonization is culture in a selective medium, but PCR has a high sensitivity and specificity.

Objectives: The goal of this study was to estimate the colonization of GBS in rectum of neonates of high-risk mothers by culture and PCR method.

Patients and Methods: Samples were taken from rectal mucosa of 154 neonatesof high-risk mothers for GBS by swabs. Samples were tested by standard culture using Todd Hewitt broth and blood agar and also by PCR using primers specific for $c f b$ gene.

Results: Of 154 neonates, Culture identified 17 (11\%) neonates as colonized by GBS; and the PCR assay could identify 27 (17\%) neonates with positive results for GBS. Mothers age range was 17-40 years ( $m e a n=26.1 \pm 5.1)$. Maternal age was significantly lower in PCR positive group $(\mathrm{P}$ $=0.038$ ) and in culture positive group $(\mathrm{P}=0.015)$. Using culture as the gold standard, sensitivity, NPV, specificity, and PPV of PCR were $100 \%$, $100 \%, 92 \%$, and $62 \%$, respectively. The time required for PCR assay and culture were 2 hours and 36 hours, respectively.

Conclusions: This study showed that the incidence of GBS in Iranian high-risk neonates is high, so we strongly recommend screening of high-risk neonates for detection of GBS.
\end{abstract}

Keywords:Streptococcus agalactiae; Infant, Newborn; Colonization

\section{Background}

Group B Streptococcus is a facultative gram-positive diplococcic, which can colonize the vagina, rectum, urethra, umbilicus, ear and pharyngeal site. Risk factors for rectovaginal colonization are lower age, multi-sexual partners, and infrequent hand washing. Vertical transmission from colonized mothers to their infants occurs in $41-72 \%$ of cases, and only $1 \%-2 \%$ of colonized neonates develop invasive GBS disease, pneumonia and bacteremia in approximately $80 \%$ of cases, meningitis in $10 \%$, and death in rare instances (4\%) (1). GBS colonization in pregnant women may result in neonatal colonization and invasive disease; hence, maternal screening of GBS colonization seems to be crucial. Maternal factors associated with early streptococcal invasive disease in neonates are delivery before 37 weeks gestation, premature rupture of membrane more than 18 hours and intrapartum fever (2). There are different reports on GBS colonization in pregnant woman from Iran (22.7\%) (3) (11.2\%) (4) 10.2\% (5)3\% (6) and other regions such as $20 \%$ in Taiwan (7) $15.3 \%$ in Lithuania (8) and (6.2\%) in China (9), this difference might be resulted from the number of partners and sexual habits in different cultures. Studies on neonatal colonization in Iran show different results. It was detected in $58.3 \%$ of dry umbilical cords (10) and 9.1\% of tracheal secretions of intubated neonates due to respiratory distress in neonatal intensive care unit (NICU) (11).

This study offers a novel investigation to detect rectal colonization in neonates of high-risk pregnancies (before 37 weeks gestation, premature rupture of membrane more than 18 hours and intrapartum fever) (2) to determine the colonization of Streptococcus group B by culture and PCR method.

\section{Objectives}

The study hypothesis was to estimate the power of PCR in comparison to culture method in detection of GBS colonization in study cases. may be the cause of sepsis in colonized neonates. This study offers a novel investigation for detection of rectal colonization in neonates of high-risk pregnancies (before 37 weeks gestation, premature rupture of membrane more than 18 hours and intrapartum fever) to determine the colonization of Streptococcus group B by culture and PCR method.

Copyright @ 2014, Pediatric Infections Research Center. This is an open-access article distributed under the terms of the Creative Commons Attribution-NonCommercial 4.0 International License (http://creativecommons.org/licenses/by-nc/4.0/) which permits copy and redistribute the material just in noncommercial usages, provided the original work is properly cited. 


\section{Patients and Methods}

This study was implemented on neonates of mothers with high-risk pregnancies from September 2009 to April 2010 in Imam Hossein Hospital (Tehran, IR Iran). Sampling was performed from neonatal rectal specimens during delivery by midwives educated on implementation of rectal swabbing. Informed consent was obtained from mothers. The study was approved by ethics committee of Shahid Beheshti University of Medical Sciences.

One hundred and fifty four neonates of high-risk mothers were included in the study. The exclusion criteria were GBS bacteriuria and planned cesarean section without membrane rupture in mothers. Sample size was calculated by considering a $15 \%$ positive result rate and delicacy of $0.05 \%$ resulted from 102 cases. Midwives obtained the specimens from neonate's rectum immediately after delivery. The double swab was placed into Stuart's transport medium (one for culture and the other for the PCR assay) and delivered to the microbiology laboratory (Pasture Institute of Iran) in 12 hours.

\subsection{Culture Identification of GBS}

Swab specimens were plated on $5 \%$ sheep blood agar and then into the LIM selective enrichment broth (ToddHewitt broth with $15 \mu \mathrm{g} / \mathrm{mL}$ nalidixic acid and $10 \mu \mathrm{g} / \mathrm{mL}$ colistin). After overnight incubation, the broths were subcultured onto 5\% sheep blood agar. Solid and liquid media were incubated at $35^{\circ} \mathrm{C}$ with $5 \% \mathrm{CO}_{2}$, and solid media were read daily for two days. GBS was identified as follows: the presence of catalase-negative, beta-hemolytic colonies and a positive reaction for the GBS antigen by a slide agglutination test (PathoDx; Diagnostic Products Corporation, Los Angeles, CA), as recommended by the CDC guidelines (12). Non hemolytic colonies were tested for the GBS antigen reaction, based on colony appearance and catalase-negative and bile esculin-sensitive reactions.

\subsection{Nucleic Acid Extraction for PCR Assay}

In total, $0.5 \mathrm{~mL}$ of selective broth was centrifuged and the pellet was extracted by PCR template purification kit according to the manufacturer protocol (Roche, Germany).Aliquots of the remaining incubated LIM broth were frozen at $-70^{\circ} \mathrm{C}$ immediately after the antigen detection and PCR assays were performed with batched samples.

\subsection{PCR Assay}

For each reaction mixture, $5 \mu \mathrm{L}$ of the extracted material was added to $20 \mu \mathrm{L}$ of PCR reagent. Briefly, primers Strep B1 (5'-TTTCACCAGCTGTATTAGAAGTA-3') and StrepB2 (5'-GTTCCCTGAACATTATCTTTGAT-3') amplify a 153-bp fragment of the $c f b$ gene (13). Each $20 \mu \mathrm{L}$ reaction volume contained $2 \mu \mathrm{L}$ 10x PCR buffer (Roche Diagnostics), 0.4 $\mu \mathrm{M}$ each primer, $0.1 \mathrm{U}$ of uracil-DNA glycosylase (UNG; Roche Diagnostics), $2.0 \mathrm{mM} \mathrm{MgCl}_{2}$, one unit of Taq DNA polymerase and $5 \mu \mathrm{L}$ of DNA extract. As an internal con- trol, all the extracted DNAs were checked by universal primers which amplify the conserved region of 23s rDNA (14). Purified DNA from a known GBS strain, confirmed by Lancefield Capillary Precipitin Methods (Gibco, USA) was used as positive control in two dilutions corresponding to $10^{4}$ and $10^{2}$ bacterial genomes. As a negative control, sterile water was added instead of DNA template. A positive control and one or two negative controls were included in each run. Strict precautions to prevent carryover of amplified DNA were used. Thermocycling conditions were optimized to one cycle at $95^{\circ} \mathrm{C}$ for 5 minutes, followed by 45 cycles of 45 seconds at $94^{\circ} \mathrm{C}, 45$ seconds at $57^{\circ} \mathrm{C}$ and 45 seconds at $72^{\circ} \mathrm{C}$. The amplified reaction products were analyzed by electrophoresis on $2 \%$ agarose gels.

\subsection{Data Analysis}

The information of maternal age, preterm $<37$ weeks or term delivery, and culture and PCR results were recorded and analyzed by using SPSS (PASW Statistics 18), sensitivity, specificity, positive predictive value and negative predictive value and likelihood ratio calculation were performed and the confidence interval was calculated by Wilson Scored Method. P value $<0.05$ estimated by t-test was considered as significant.

Table 1. Culture and PCR Results in Different Groups of HighRisk Neonates ${ }^{\mathrm{a}}$, $\mathrm{b}$

\begin{tabular}{lccc}
\hline Groups & Culture + & PCR+ & Culture PCR+ \\
\hline Preterm $(\mathbf{n}=\mathbf{7 8})$ & $8(10)$ & $12(15)$ & $12(15)$ \\
PROM $(\mathbf{n}=\mathbf{3 9})$ & $5(12)$ & $8(20)$ & $8(20)$ \\
Fever $(\mathbf{n}=\mathbf{3 7})$ & $4(10)$ & $7(18)$ & $7(18)$ \\
\hline
\end{tabular}

${ }^{\mathrm{a}}$ Data are presented in No.(\%).

b Abbreviations: PCR, polymerase chain reaction; PROM, Premature Rupture Of Membrane

Table 2. PCR and Culture Results and Maternal Age in High-Risk Neonates ${ }^{\mathrm{a}}$

\begin{tabular}{rcc}
\hline Tests & Maternal Age & Pvalue \\
\hline PCR & & 0.04 \\
+ & $24.3 \pm 4.3$ & \\
- & $26 \pm 5.2$ & \\
Culture & & 0.015 \\
+ & $23 \pm 4.4$ & \\
- & $26 \pm 5.1$ & \\
\hline
\end{tabular}

${ }^{\mathrm{a}}$ Data are presented in Mean \pm SD.

Table 3. Culture Results Based on Positive and Negative PCR Cases

\begin{tabular}{lcc}
\hline & Culture+ & Culture- \\
\hline PCR+ & 17 & 10 \\
PCR- & 0 & 127 \\
\hline
\end{tabular}


Shirvani F et al.

Table 4. Sensitivity, Specificity, PPV, NPV, LR+ and LR-Using Culture as the Gold Standard ${ }^{\text {a }}$

\begin{tabular}{lcccccc}
\hline Sensitivity & Specificity & PPV & NPV & Accuracy & LR+ & LR- \\
\hline $\mathbf{1 0 0 . 0 0} \%$ & 92.70 & 62.96 & 100.00 & 93.51 & 13.7 & 0 \\
$\mathbf{8 1 . 5 7 - 1 0 0}$ & $87.08-95.99$ & $44.23-78.47$ & $97.06-100$ & $88.46-96.43$ & $7.543-24.882$ & $0-0.385$ \\
\hline
\end{tabular}

${ }^{a}$ Abbreviations: LR+, positive likelihood ratio; LR-, negative likelihood ratio; NPV, negative predictive value; PPV, positive predictive value.

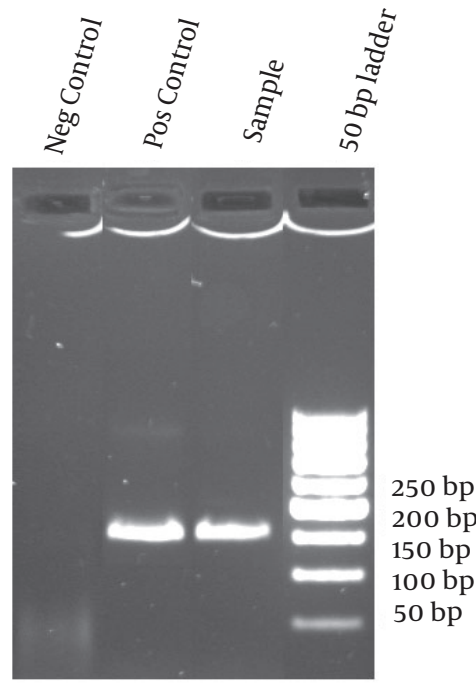

Figure 1. PCR product by Gel Electrophoresis in Positive Sample and Negative and Positive Control

\section{Results}

In total, 154 neonates entered the study based on the inclusion criteria,39 cases were PROM (Premature Rupture of Membrane) (25\%), 37 cases had fever (24\%), and 78 cases had gestational age less than 37 weeks (51\%), 27 cases (17\%) were PCR positive and 17 cases (11\%) were culture positive.

Twelve (15\%) of preterm cases (78) and 8 (20\%) of PROM cases and 7 (18\%) of fever case (37) were PCR and culture positive, the number of culture positive cases were less than PCR positive cases in three groups, all culture positive cases were PCR positive simultaneously (Table 1). There was no significant difference between high-risk groups in PCR and culture positive and negative groups, Mothers age range was $17-40$ years $($ mean $=26.1 \pm 5.1$ ). Maternal age was significantly lower in PCR positive group $(\mathrm{P}=0.038)$ and in culture positive group $(\mathrm{P}=0.015)$ (Table 2). Using culture as the gold standard, sensitivity, specificity, PPV, NPV, LR+ and LR-were 100\%, 92.7\%, 62.9\%,100\%, 13.7 and 0 respectively (Tables 3 and 4, and Figure 1).

\section{Discussion}

The likelihood ratio of GBS infection in a neonate born to a mother with one or more risk factors being infected with GBS is about 3.9-fold higher than the background risk. The individual risk factors carry different 'weights', in which intrapartum fever is associated with the highest risk and prolonged rupture of membranes associated with the lowest risk $(15,16)$. This study estimated GBS colonization in rectum of Iranian neonates, and 17\% PCR positive rate in neonates of high-risk pregnancy is high enough to be considered important and if other sites such as umbilicus and ear were added, the rate might be increased accordingly, so there may be probable missed cases of positive GBS colonization in our study. Higher colonization may result in higher sepsis rate in neonates, and increase in bacteriologic techniques sensitivity may result in higher positive cases of Streptococcus group B sepsis in our setting.

As a preventive strategy of neonatal sepsis with GBS, mothers colonized with GBS are recognized, and treated. Maternal GBS screening and intrapartum antibiotic prophylaxis showed that intrapartum antibiotic prophylaxis could reduce the incidence of early-onset GBS infection by $70 \%$ (17). Different strategies are described to prevent GBS infection in neonates. Screening based strategy (antibiotic prophylaxis given to all colonized mothers) and risk-based strategies (antibiotic prophylaxis given to all high-risk mothers) are implemented to reach this goal $(18,19)$. In resource-limited countries, implementation of culture, even in high-risk pregnant women is difficult, on the other hand, overuse of antibiotics in intrapartum period and neonates might be prevented. In aprospective study in Friuli-Venezia Giulia (north-eastern Italy), complete blood count and blood culture for GBS for all infants at risk, with a standardized physical examination had no advantage over only standardized physical examination on the onset of signs of possible sepsis and beginning the treatment, and significantly fewer infants were treated with antibiotics in the second group (20). Therefore, we need more investigations on GBS colonization and infection in our mothers and their neonates. Different methods for GBS screening are available, which are traditional culture and PCR, culture method is time consuming but more available, quantitative PCR may also offer the advantage of reduced time-to-results, and increased positive results, making it useful as an intrapartum screening method (21-23).Studies on different culture and PCR methods in maternal and neonatal detection of GBS colonization are in accordance with the results of our study. Among 375 women, with vaginal and rectal sampling, in Mirzak- 
hochakkhan Hospital Tehran, IR Iran (2011), 35 (9.3\%) were identified as carriers of group B streptococci by cultures of specimens, compared to $42(11.2 \%)$ based on the PCR assay (4). Goodrich et al. compared routine culture and two real-time polymerase chain reaction (PCR) assays for detection of GBS: the light cycler (LC) Strep B analytespecific reagents (ASRs)and the BD GeneOhm Strep B (BDStrep B) test, detection rate increased from 3.0\% to 3.5\% with PCR, the sensitivity/specificity of the LC Strep B ASR was $100 \% / 95.9 \%$, and for BD-Strep B test was $92.5 \% / 92.5 \%$ by using culture as the gold standard method (24). Gavino et al. performed both rapid test (PCR) and intrapartum culture on 55 subjects as GBS screening at 35-37 weeks of gestational age, GBS colonization rate was $43.6 \%$ by culture and $62 \%$ by PCR. Sensitivity and specificity of the PCR test were $95.8 \%$ and $64.5 \%$ respectively (23). Antenatal GBS screening was performed by Davis et al. using two combined vaginal/anal with rapid molecular diagnostic test (IDI-Strep B; infection diagnostic) and culture for intrapartum GBS detection after 36 weeks of gestational age in 5 North American centers during September 2001 to May 2002. In total, 881 women were recruited into the study. The overall intrapartum GBS colonization rate was 18.6\% in study sites. The sensitivity of IDI-Strep B in study sites ranged from $85 \%$ to $99 \%$,and specificity ranged from $93 \%$ to $100 \%$ (22). Rallu et al. found culture positive rectovaginal specimens as screening tests from two hundred six LIM enrichment broth samples in 62 cases and PCR positive in 64 cases (25). In concern with the results of this study, we recommend to consider culture (more available) and PCR method to detect GBS colonization and infection in neonates of high-risk mothers. PCR method is preferable because of $100 \% \mathrm{PPV}$, but still we can rely on the result of culture because of its $100 \%$ specificity and very low false positive rate, although its lower sensitivity $62.9 \%$ shows a higher false negative rate. We recommend to consider group B Streptococcus as an important pathogen in neonatal sepsis and including GBS screening test in evaluation of high-risk pregnant women with higher chance of colonization with this organism to prevent the colonization and sepsis in their neonates.

\section{Acknowledgements}

We appreciate all the staffs and associated workers from obstetric and Neonatal ward of Imam Hossein Hospital and Pasteur Institute of Iran for their cooperation.

\section{Authors' Contribution}

All author contributed same in this study.

\section{Financial Disclosure}

The authors declare no competing financial interests and conflict of Interest.

\section{Funding/Support}

Financial support was from Pasteur Institute of Iran.

\section{References}

1. Schuchat A. Group B streptococcus. Lancet. 1999;353(9146):51-6.

2. Feigin RD, Demmaler-Harrison GJ, Cherry JD, Kaplan SL. Textbook of pediatric infectious diseases. United States: Saunders-Elsevier; 2009.

3. Javanmanesh F, Eshraghi N. Prevalence of positive recto-vaginal culture for Group B streptococcus in pregnant women at 35-37 weeks of gestation. Med J Islam Repub Iran. 2013;27(1):7-11.

4. Bakhtiari R, Dallal MS, Mehrabadi J, Heidarzadeh S, Pourmand M Evaluation of culture and PCR methods for diagnosis of group B streptococcus carriage in Iranian pregnant women. Iran J Public Health. 2012;41(3):65-70.

5. Shirvani F, Momenzadeh A, Aslani MM, Shahrochi N, Torabi SJ, Khalegi R. Prevalence of vaginal colonization of group B streptococcus in Tehran,s women and its relation to colonization in newborns. Pejouhandeh J.1998;2(4):121-5.

6. Fatemi F, Pakzad P, Zeraati H, Talebi S, Asgari S, Akhondi MM, et al Comparative Molecular and Microbiologic Diagnosis of Vaginal Colonization by Group B Streptococcus in Pregnant Women during Labor. Iran J Basic Med Sci. 2010;13(4):183-8.

7. Yu HW, Lin HC, Yang PH, Hsu CH, Hsieh WS, Tsao LY, et al. Group B streptococcal infection in Taiwan: maternal colonization and neonatal infection. Pediatr Neonatol. 2011;52(4):190-5.

8. Barcaite E, Bartusevicius A, Tameliene R, Maleckiene L, Vitkauskiene A, Nadisauskiene R. Group B streptococcus and Escherichia coli colonization in pregnant women and neonates in Lithuania. Int J Gynaecol Obstet. 2012;117(1):69-73.

9. Yang MJ, Sun PL, Wen KC, Chao KC, Chang WH, Chen CY, et al. Prevalence of maternal group B streptococcus colonization and vertical transmission in low-risk women in a single institute. $J$ Chin Med Assoc. 2012;75(1):25-8.

10. Nourian M, Allaii F, Heidari A. Comparison of the effect of alcohol $70 \%$ versus dry cord care on cord bacterial colonization and cord separation time among newborns. PakJMed Sci.2009;25(1):103-7.

11. Khosravi N, Noorbakhsh S, Tabatabaei A, Ghavami Y. Prevalence of streptococcus group B in tracheal tube secretions o fneonates with respiratory distress: a brief report. Tehran Univ Med J 2013;70(11):729-34.

12. Schrag S, Gorwitz R, Fultz-Butts K, Schuchat A. Prevention of perinatal group B streptococcal disease. MMWR Recomm Rep. 2002;51(11):1-22.

13. Convert M, Martinetti Lucchini G, Dolina M, Piffaretti JC Comparison of LightCycler PCR and culture for detection of group B streptococci from vaginal swabs. Clin Microbiol Infect. 2005;11(12):1022-6.

14. Lee DY, Shannon K, Beaudette LA. Detection of bacterial pathogens in municipal wastewater using an oligonucleotide microarray and real-time quantitative PCR. $J$ Microbiol Methods. 2006;65(3):453-67.

15. Royal College of Obstetricians and Gynaecologists. Prevention of early onset neonatal group B streptococcal disease Guideline. 2012. Available from: http://www.rcog.org.uk/resources/Public/ GroupB_strep_no36.pdf.

16. Law MR, Palomaki G, Alfirevic Z, Gilbert R, Heath P, McCartney C, et al. The prevention of neonatal group B streptococcal disease: a report by a working group of the Medical Screening Society. $J$ Med Screen. 2005;12(2):60-8.

17. Schrag SJ, Zywicki S, Farley MM, Reingold AL, Harrison LH, Lefkowitz LB, et al. Group B streptococcal disease in the era of intrapartum antibiotic prophylaxis. N Engl J Med. 2000;342(1):15-20.

18. Heath PT, Schuchat A. Perinatal group B streptococcal disease. Best Pract Res Clin Obstet Gynaecol. 2007;21(3):411-24.

19. Pettersson K. Perinatal infection with Group B streptococci. Semin Fetal Neonatal Med. 2007;12(3):193-7.

20. Cantoni L, Ronfani L, Da Riol R, Demarini S, Perinatal Study 


\section{Shirvani F et al.}

Group of the Region Friuli-Venezia G. Physical examination instead of laboratory tests for most infants born to mothers colonized with group B Streptococcus: support for the Centers for Disease Control and Prevention's 2010 recommendations. J Pediatr. 2013;163(2):568-73.

21. Bergseng H, Bevanger L, Rygg M, Bergh K. Real-time PCR targeting the sip gene for detection of group B Streptococcus colonization in pregnant women at delivery. J Med Microbiol. 2007;56(Pt 2):223-8.

22. Davies HD, Miller MA, Faro S, Gregson D, Kehl SC, Jordan JA. Multicenter study of a rapid molecular-based assay for the diagnosis of group B Streptococcus colonization in pregnant women. Clin Infect Dis. 2004;39(8):1129-35.
23. Gavino M, Wang E. A comparison of a new rapid real-time polymerase chain reaction system to traditional culture in determining group B streptococcus colonization. Am J Obstet Gynecol. 2007;197(4):3880-4.

24. Goodrich JS, Miller MB. Comparison of culture and 2 real-time polymerase chain reaction assays to detect group B Streptococcus during antepartum screening. Diagn Microbiol Infect Dis. 2007;59(1):17-22.

25. Rallu F, Barriga P, Scrivo C, Martel-Laferriere V, Laferriere C. Sensitivities of antigen detection and PCR assays greatly increased compared to that of the standard culture method for screening for group B streptococcus carriage in pregnant women.J Clin Microbiol. 2006;44(3):725-8. 